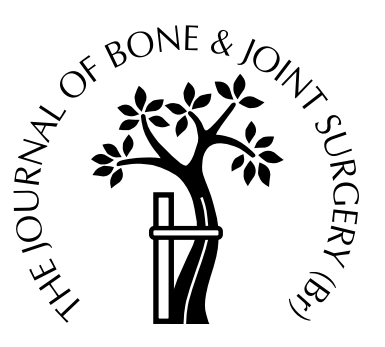

\title{
The treatment of congenital brachymetatarsia by one-stage lengthening
}

\author{
Goo Hyun Baek, Moon Sang Chung \\ From Seoul National University College of Medicine, Seoul, Korea
}

$\mathbf{W}$ e performed one-stage lengthening using intercalary autogenous bone graft in 34 metatarsals and seven proximal phalanges in 21 patients with congenitally short metatarsals. At operation, in order to decrease the tension in the surrounding soft tissues, we gradually distracted the osteotomies of the affected bones for 20 to 30 minutes. The patients, all women, were followed up for a mean period of 2.1 years ( 1 to 6.5 ).

The average gain in length for the 34 metatarsal procedures was $14 \mathrm{~mm}$ (6 to 21 ), equivalent to an increase of $32 \%$ (11 to 51), and for the seven proximal phalangeal lengthenings $8 \mathrm{~mm}$ (5 to 11 ), an increase of $54 \%$ (47 to 65 ). There was no evidence of neurovascular impairment.

The technique of gradual distraction during operation is simple and effective. It overcomes the disadvantages of one-stage lengthening such as a small gain in length and neurovascular damage.

J Bone Joint Surg [Br] 1998;80-B:1040-4.

Received 2 January 1998; Accepted 1 April 1998

Congenital brachymetatarsia describes shortening of the metatarsal bone caused by premature closure of the epiphysis. The fourth toe is most commonly involved, although any or multiple metatarsals may be affected. The deformity has a strong female predilection with a reported sex ratio of 98:4. ${ }^{1}$ Cosmesis may be a problem, especially in young women.

Surgical correction with autogenous bone graft from the calcaneus was first reported in $1969^{2}$ and since then many techniques have been described. The most widely-used procedures are either one-stage lengthening with intercalary ${\text { bone } \text { graft }^{1-3} \text { or gradual lengthening by callotasis. }}^{4-6}$ Each

G. H. Baek, MD, Assistant Professor

M. S. Chung, MD, Professor and Chairman

Department of Orthopaedic Surgery, Seoul National University College of

Medicine, 28 Yongon-Dong, Chongro-Gu, Seoul 110-744, Korea.

Correspondence should be sent to Dr M. S. Chung.

(C1998 British Editorial Society of Bone and Joint Surgery

0301-620X/98/58701 \$2.00

1040 has its advantages and disadvantages. One-stage lengthening needs a shorter period to bony union and has less morbidity, but produces a proportionally smaller increase and more neurovascular complications than the gradual procedure. ${ }^{7,8}$

Patients and Methods

Between 1989 and 1995, we performed 41 one-stage lengthenings (34 metatarsals and seven proximal phalanges) using intercalary autogenous bone graft in 21 patients with congenital brachymetatarsia. To achieve the optimal length of the toe, six proximal phalanges were lengthened with the metatarsal of the same ray. All 21 patients were women and their average age was 16 years (10 to 36). All complained of the appearance of the short toe(s), and ten had occasional pain around adjacent metatarsal heads when walking. In 11 patients the condition was unilateral with the fourth metatarsal involved in ten and the first metatarsal in one. Of the ten patients with bilateral involvement, six showed shortening of the fourth metatarsal, two of the first and fourth metatarsals, one of the first, third and fourth metatarsals, and one of the fourth metatarsal and adjacent proximal phalanx. In 19 patients, we used intercalary autogenous iliac-bone grafts (Figs 1 and 2). In two patients with bilateral short first and fourth metatarsals, the second and third metatarsals were shortened and the excised bone used to lengthen the fourth metatarsal (Fig. 3). There was a family history in three patients. Four patients had associated brachymetacarpia which was bilateral in two and unilateral on the same side in the other two. After operation the patients were followed up for a mean of 2.1 years ( 1 to 6.5).

Operative technique. A dorsal longitudinal incision was made over the affected metatarsal and the interosseous muscles on both sides were detached by sharp dissection (Fig. 4). The extensor tendons were retracted and the metatarsal shaft exposed subperiosteally. The affected metatarsal was divided transversely at the level of the midshaft. A Kirschner (K) wire of 1.14 or $1.57 \mathrm{~mm}$ was driven into the metatarsal head from the osteotomy site of the distal fragment, and then distally through the proximal, middle and distal phalanges. The wire was retrieved distally until its tip was seen on the surface of the osteo-

THE JOURNAL OF BONE AND JOINT SURGERY 


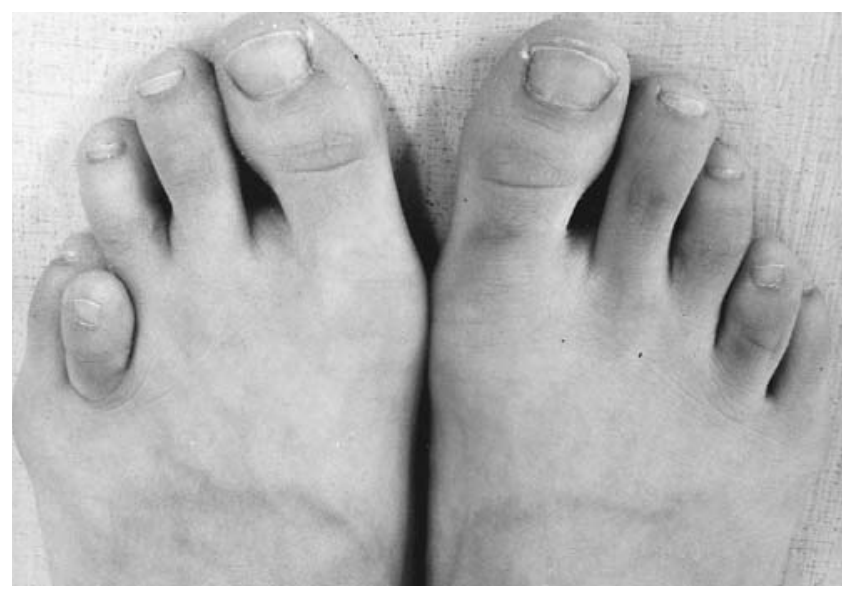

Fig. 1a

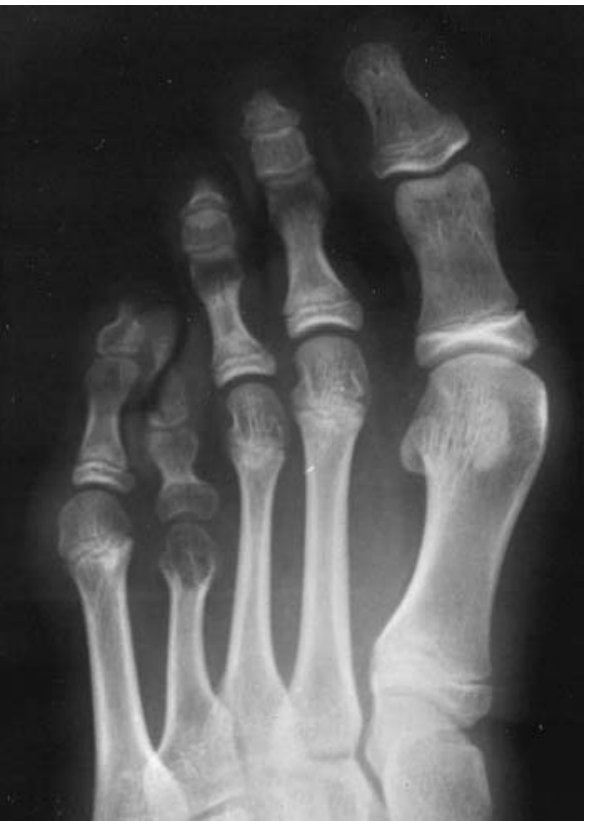

Fig. 1c

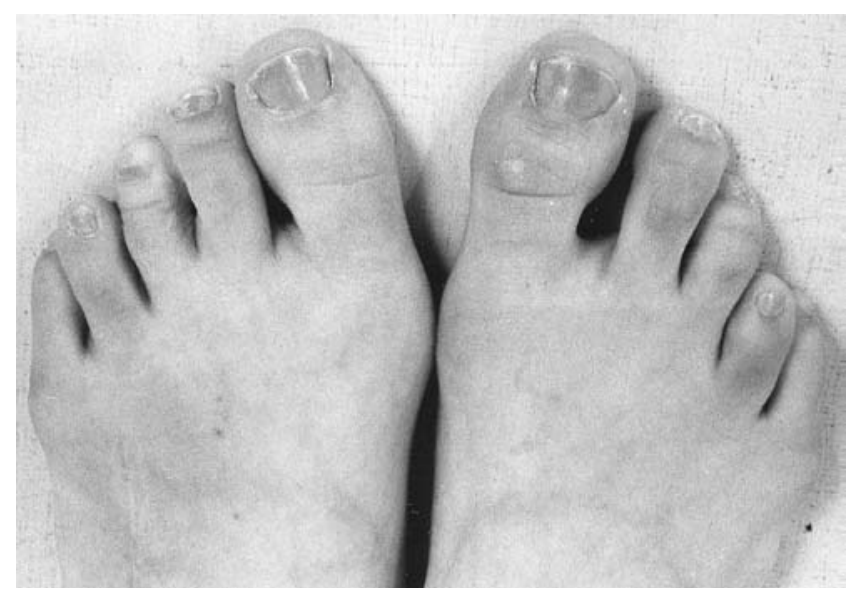

Fig. 1b

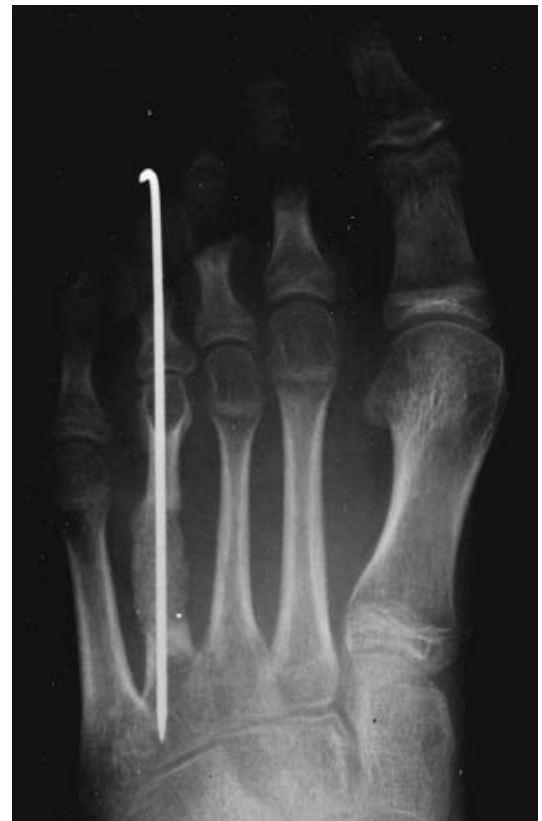

Fig. 1d

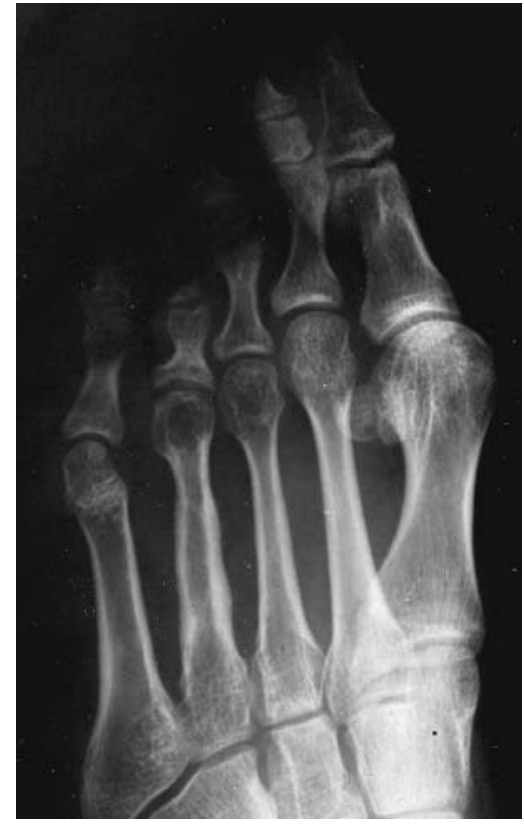

Fig. 1e

A 12-year-old girl with brachymetatarsia of the left fourth toe before (a) and one year seven months after operation (b). The radiographs show an anteroposterior view before operation (c), a gain in length of $21 \mathrm{~mm}(51 \%)$ and restoration of the metatarsal parabola (d). The iliac bone graft was completely remodelled (e).

tomy; this prevented subluxation of the metatarsophalangeal and interphalangeal joints during distraction. The osteotomy was then gradually distracted by an Inge bone spreader for 20 to 30 minutes to decrease soft-tissue tension. Usually, initial distraction of 7 or $8 \mathrm{~mm}$ by the spreader was easily achieved. The ratchet of the spreader was then used for gradual distraction; every click of the ratchet was approximately equivalent to $1.5 \mathrm{~mm}$ and was maintained for three minutes. A bicortical iliac-bone graft was then taken and shaped to fill the gap in the lengthened bone and predrilled to allow easy insertion of the K-wire. It was placed in the gap of the distracted osteotomy and the K-wire passed across to achieve fixation from the distal phalanx to the base of the metatarsal or adjacent tarsal bone.
A below-knee walking cast was applied. The cast and Kwire were removed after seven to ten weeks when radiographs showed solid union. Full weight-bearing was allowed at about 12 weeks after operation. The procedure for lengthening the proximal phalanx was similar.

\section{Results}

In the 41 bones the mean gain in length and percentage increase were $13 \mathrm{~mm}$ (5 to 21 ) and $35 \%$ (11 to 65), respectively. In the 34 metatarsals the mean gain in length was $14 \mathrm{~mm}$ (6 to 21), which was equivalent to an increase of $32 \%$ (11 to 51 ). The corresponding figures for the seven proximal phalangeal procedures were $8 \mathrm{~mm}$ (5 to 11) and $54 \%$ (47 to 65$)$. 


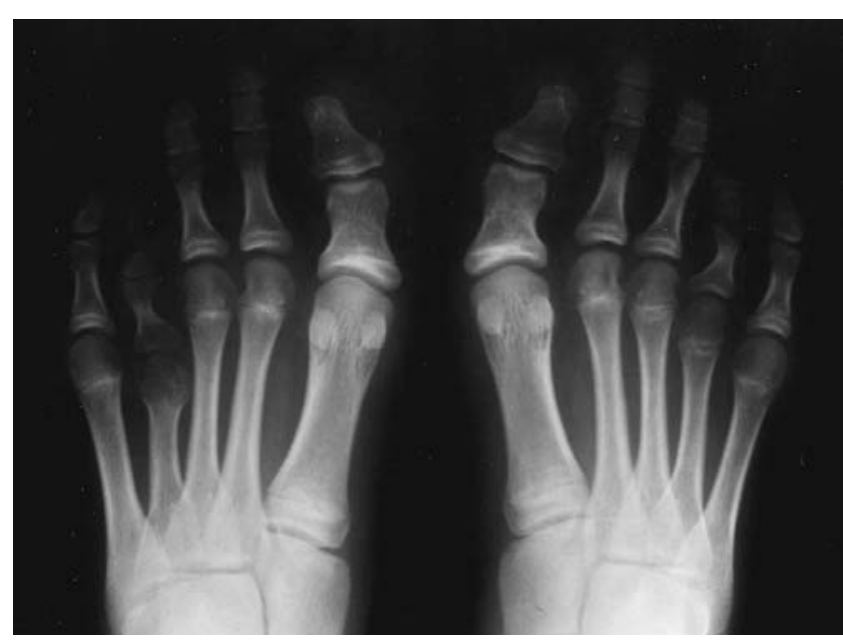

Fig. 2a

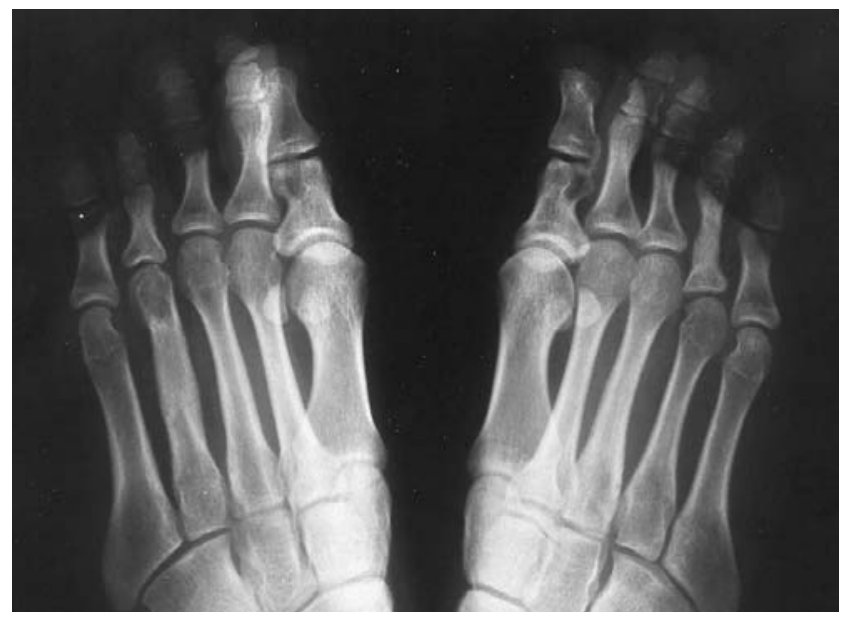

Fig. 2c

Nine complications occurred. There were four cases of stiffness of the metatarsophalangeal joint, two of fracture, one of loss of fixation, one of delayed union and one of nonunion. Stiffness was defined as a reduction in the range of movement of the metatarsophalangeal joint by more than $50 \%$. The two fractures occurred 3.5 and 4 months after surgery at the proximal junction of the grafted bone and the metatarsal; both were undisplaced and were treated by a below-knee cast for four weeks. In the patient with delayed union, this was achieved after six months of immobilisation. The nonunion of the proximal phalanx was asymptomatic.

All patients were satisfied with the cosmetic results. They could walk on tiptoe and had no limitation in the activities of daily life. Two had mild pain in the forefoot when jogging.

\section{Discussion}

Soft tissues such as tendons, muscles, joint capsules, ligaments, skin and fascia show time-dependent viscoelastic

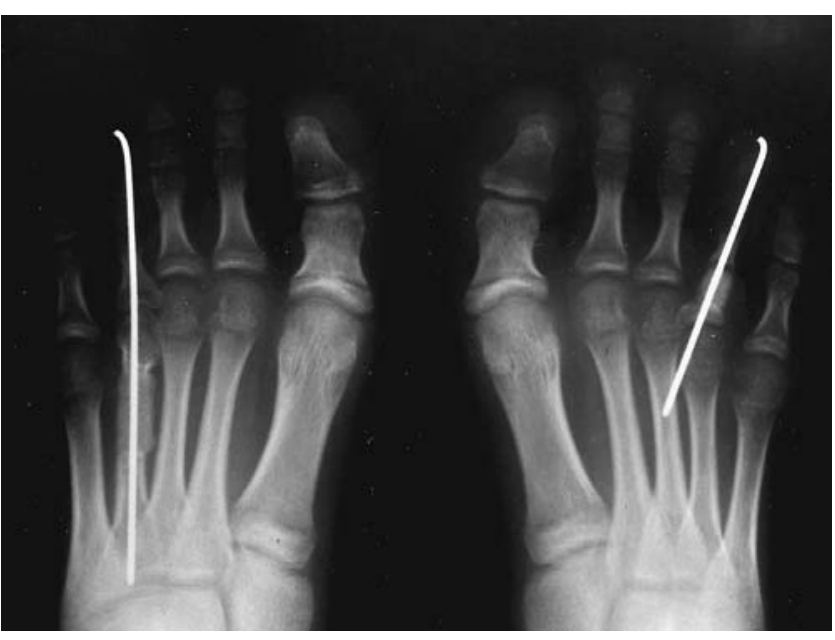

Fig. 2b

Radiographs of a 12-year-old girl showing shortening of the left fourth metatarsal and the right fourth proximal phalanx (a), the gain in length of $20 \mathrm{~mm}(41 \%)$ in the metatarsal and $11 \mathrm{~mm}(65 \%)$ in the proximal phalanx (b), and good maintenance of the metatarsal parabola at one year and eight months (c).

properties that reflect the complex interaction of collagen and ground substances. ${ }^{9}$ Creep and stress relaxation are important viscoelastic characteristics. The first denotes an increase in deformation over time under a constant load. Rapidly applied forces will cause the soft tissues to react by stiffening, but when a constant distraction load is applied, they respond in a more compliant or ductile manner and plastic deformation results. The deformation and elongation of the soft tissues are continuous, but slow, and require sufficient time. Stress relaxation denotes a decline in stress over time under constant deformation; its occurrence is due to the realignment and elongation of soft tissues held in a fixed position for a prolonged period of time.

Our technique of gradual distraction at operation involved the use of creep and stress relaxation for between 20 and 30 minutes, and we were thus able to lengthen the affected bone by up to $21 \mathrm{~mm}$ without Z-plasty of the extensor tendon or V-Y plasty of skin. There were no neurovascular problems. Gradual lengthening by callotasis may involve more creep and stress relaxation than gradual distraction during the operation, but our procedure gave 


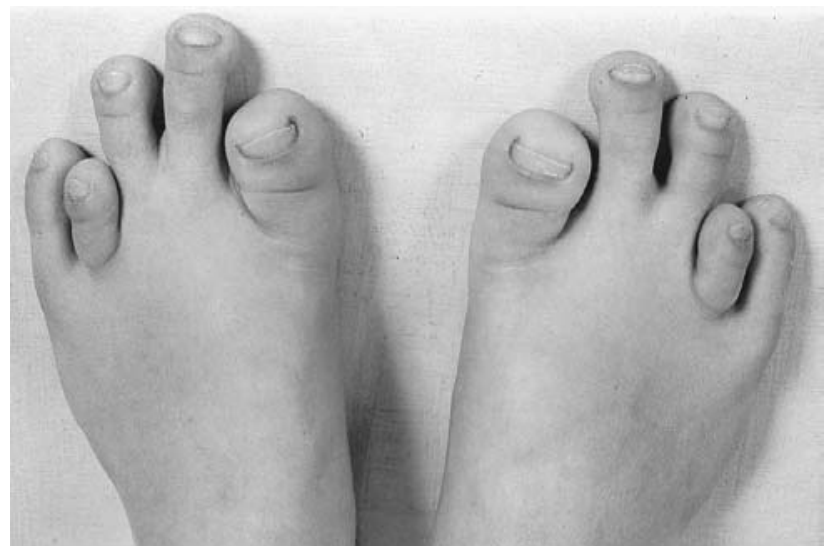

Fig. 3a

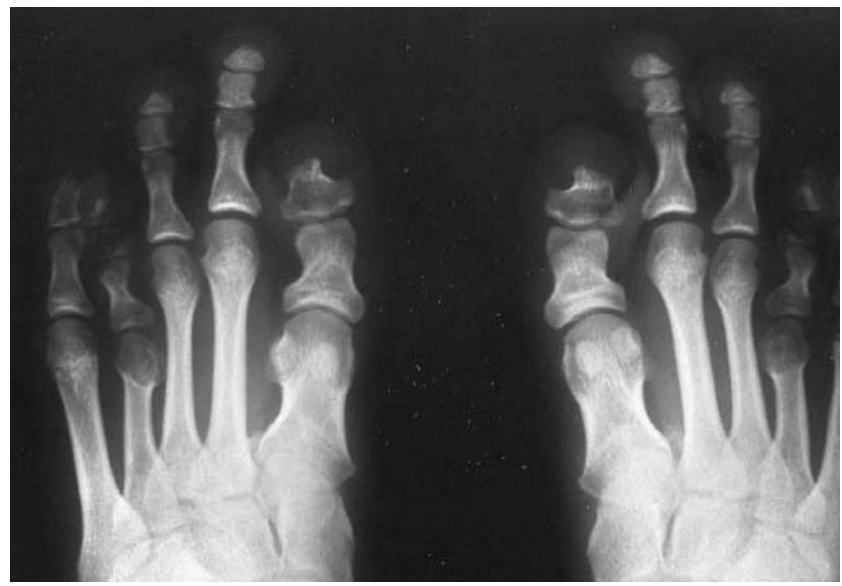

Fig. 3c

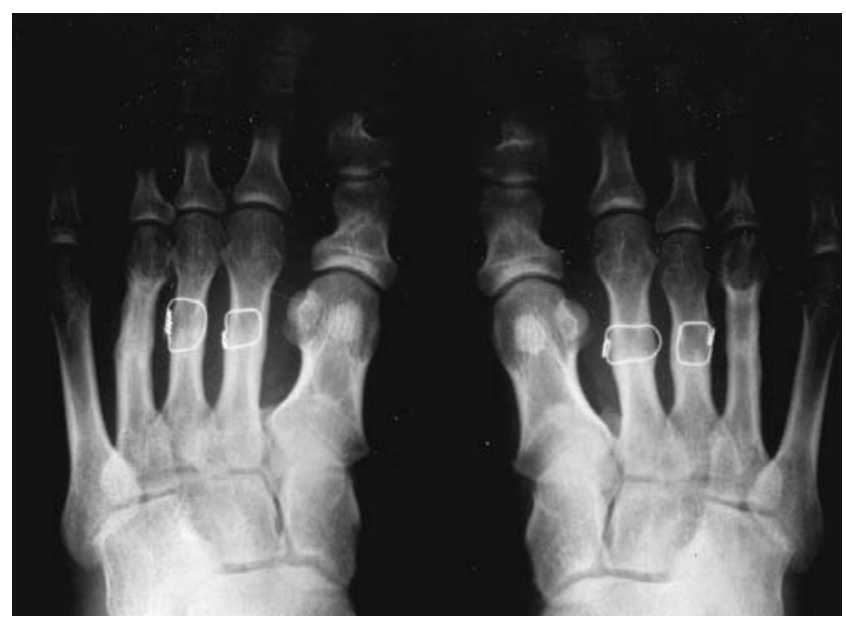

Fig. 3e

sufficient lengthening for the treatment of brachymetatarsia. We have learned by experience that constant distraction for 20 to 30 minutes is enough to lengthen the osteotomised bone and surrounding soft tissues. In the 34 cases of metatarsal lengthening, our method led to a mean gain in length of $14 \mathrm{~mm}$, a result similar to that of callotasis, which

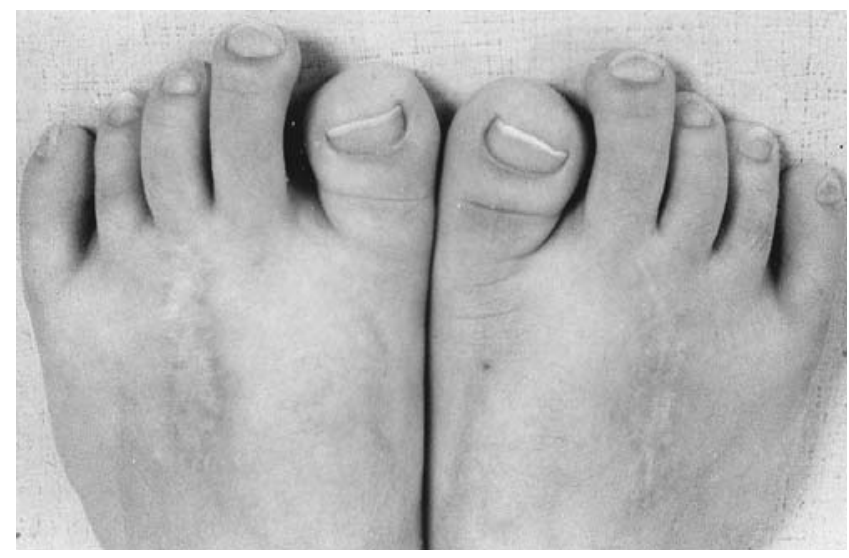

Fig. $3 b$

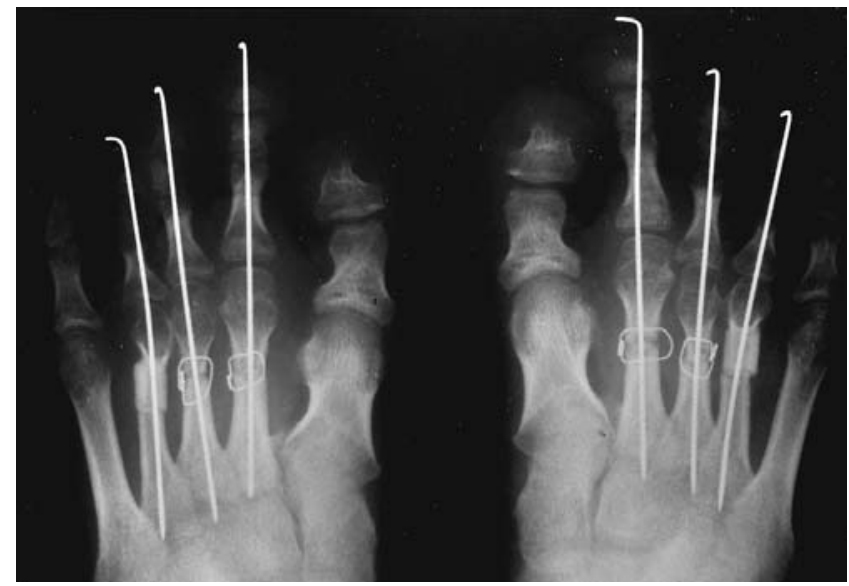

Fig. 3d

A 13-year-old girl with brachymetatarsia of the first and fourth toes on both sides before (a) and two years and seven months after operation (b). Radiographs show an anteroposterior view before operation (c), the shortened second and third metatarsals with the excised bone used to lengthen the fourth metatarsals (d) and the results after two years seven months (e).

averaged 13 to $15 \mathrm{~mm} .{ }^{4,6}$ Excessive lengthening by callotasis may cause subluxation of the metatarsophalangeal joint, ${ }^{5}$ although this risk can be minimised by longitudinal $\mathrm{K}$-wire fixation from the distal phalanx to the tarsal bone or metatarsal base of the affected ray (Fig. 4). We did not find subluxation of any metatarsophalangeal joint. 


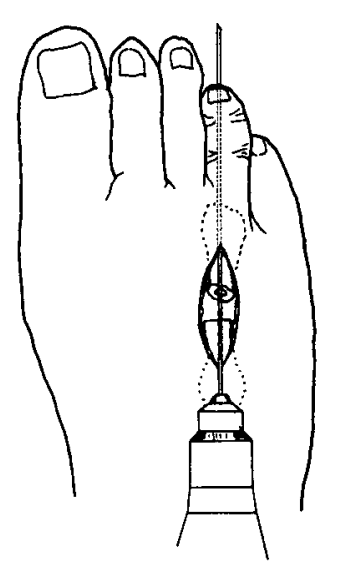

A

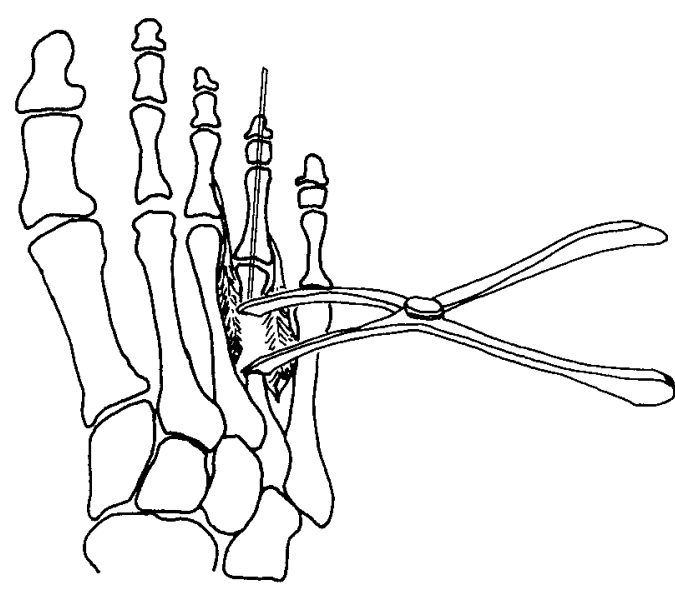

$\mathrm{B}$

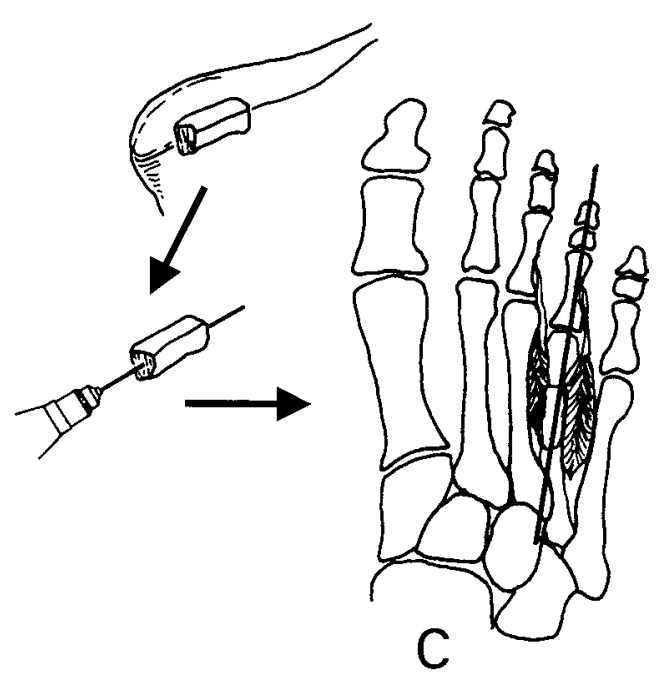

Fig. 4

Diagram of the operative technique. A K-wire is driven into the metatarsal head from the osteotomy site, and then distally through the phalanges (A). The site is distracted gradually by a bone spreader (B). The wire prevents subluxation of the metatarsophalangeal and interphalangeal joints during distraction. A bicortical iliac-bone graft is taken, predrilled, inserted into the distracted site, and fixed longitudinally with the K-wire from the distal phalanx to the tarsal bone $(\mathrm{C})$.

The disadvantages of gradual lengthening by callotasis include the time required for solid union, the possibility of nonunion, and pin-track infection. ${ }^{10}$ One-stage lengthening with intercalary bone graft may produce morbidity of the donor site, neurovascular impairment caused by rapid stretching, and a small gain in length due to the high tension of surrounding soft tissues. ${ }^{5,7}$ We believe that these disadvantages can be overcome by our technique. With callotasis the overall period of treatment, from operation to removal of the external fixator, is between 15 weeks and 4.5 months. ${ }^{4-6}$ In our series, the K-wire was removed on average 8.5 weeks after surgery, and full weight-bearing was usually allowed 12 weeks after operation.

Our experience suggests that one-stage lengthening with an intercalary bone graft is a good method for the surgical treatment of brachymetatarsia.

No benefits in any form have been received or will be received from a commercial party related directly or indirectly to the subject of this article.

\section{References}

1. Urano Y, Kobayashi A. Bone-lengthening for shortness of the fourth toe. J Bone Joint Surg [Am] 1978;60-A:91-3.

2. McGlamry ED, Cooper CT. Brachymetatarsia: a surgical treatment. J Am Podiatry Assoc 1969;59:259-64.

3. Marcinko DE, Rappaport MJ, Gordon S. Post-traumatic brachymetatarsia. J Foot Surg 1984;23:451-3.

4. Ferrandez L, Yubero J, Usabiaga J, Ramos L. Congenital brachymetatarsia: three cases. Foot Ankle 1993;14:529-33.

5. Kawashima T, Yamada A, Ueda K, Harii K. Treatment of brachymetatarsia by callus distraction (callotasis). Ann Plast Surg 1994;32: 191-9.

6. Masuda T, Matoh N, Nakajima T, Tomi M, Ohba K. Treatment of brachymetatarsia using a semicircular lengthener: 1-3 years results in 6 patients. Acta Orthop Scand 1995;66:43-6.

7. Bouchard JL. Congenital deformities of the forefoot. In: McGlamery ED, Banks AS, Darmy MS, eds Comprehensive textbook of foot surgery. Vol. 2. Baltimore, etc: Williams and Wilkins, 1992: 1191-231.

8. Takakura Y, Tanaka T, Fujii T, Tamai S. Lengthening of short great toes by callus distraction. J Bone Joint Surg [Br] 1997;79-B:955-8.

9. Woo SL-Y, Livesay GA, Runco TJ, Young EP. Structure and function of tendons and ligaments. In: Mow VC, Hayes WC, eds. Basic orthopaedic mechanics. Second ed. Philadelphia, etc: Lippincott-Raven, 1997:209-51.

10. Smith RJ, Gumley GJ. Metacarpal distraction lengthening. Hand Clin 1985;1:417-29. 